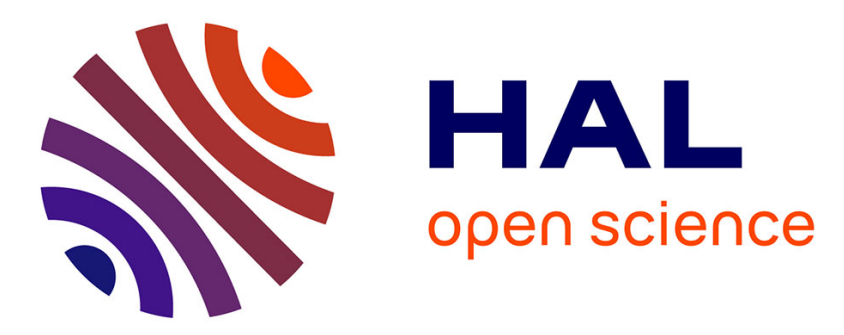

\title{
ON THE VISUALIZATION AND ANALYSIS OF FLUID-STRUCTURE INTERACTION FROM THE PERSPECTIVE OF INSTANTANEOUS INTENSITY
}

\author{
A. Romano, E. Williams, K. Russo, L. Schuette
}

\section{- To cite this version:}

A. Romano, E. Williams, K. Russo, L. Schuette. ON THE VISUALIZATION AND ANALYSIS OF FLUID-STRUCTURE INTERACTION FROM THE PERSPECTIVE OF INSTANTANEOUS INTENSITY. Journal de Physique IV Proceedings, 1992, 02 (C1), pp.C1-597-C1-600. 10.1051/jp4:19921128 . jpa-00251084

HAL Id: jpa-00251084

https://hal.science/jpa-00251084

Submitted on 1 Jan 1992

HAL is a multi-disciplinary open access archive for the deposit and dissemination of scientific research documents, whether they are published or not. The documents may come from teaching and research institutions in France or abroad, or from public or private research centers.
L'archive ouverte pluridisciplinaire HAL, est destinée au dépôt et à la diffusion de documents scientifiques de niveau recherche, publiés ou non, émanant des établissements d'enseignement et de recherche français ou étrangers, des laboratoires publics ou privés. 


\title{
ON THE VISUALIZATION AND ANALYSIS OF FLUID-STRUCTURE INTERACTION FROM THE PERSPECTIVE OF INSTANTANEOUS INTENSITY
}

\author{
A.J. ROMANO, E.G. WILLIAMS*, K.L. RUSSO and L.C. SCHUETTE* \\ Sachs/Freeman Associates, Inc., 1402 McCormick Drive, Landover, MD 20785, USA \\ *Naval Research Laboratory, Code 5132, Washington, DC 20375-5000, USA
}

\begin{abstract}
A formulation for the instantaneous structural intensity in thin cylindrical shells is presented, as well as a method for determining the tangential displacement components within a shell given a knowledge of the normal displacement and surface pressure only. These techniques are then applied to real, experimental data taken on a point-driven, fluid-loaded cylindrical shell, yielding the instantaneous intensity both within the shell and in the surrounding fluid due to an impulse delivered by the point driver. The mechanism of fluid-structure interaction in the very nearfield is briefly discussed. It is observed that in this case, only $21.5 \%$ of the total energy delivered to the fluid by the structure, radiates to the farfield, while the remaining energy is seen to be delivered back into the structure by the fluid.

Une répresentation de l'intensité vibratoire instantanée dans les structures fines et cylindriques est établie ainsi q'une méthode pour déterminer les composantes des déplacements tangentiels dans une structure dont on connaît le déplacement normale à la surface, et la pression à la surface. Ces techniques sont appliqués à des données experimentales mesuré sur un cylindre dans un fluid attaché a un vibrateur et sont utilisées pour calculer l'intensité instantanée dans la structure et dans le fluide autour de la structure due à une force impulsive delivré par la source. Le principe de l'interaction entre le fluid et la structure dans le champs trés prôche est discuté. On observe que dans ce cas, seulement $21.5 \%$ de l'énergie total delivré dans le fluid par la structure radie dans le champ lointain, et que l'énergie restante est rédelivré dans la structure par le fluide.
\end{abstract}

\section{INTRODUCTION}

Recent efforts in the area of structural intensity (1-4) have led to feasible methods for the analysis of energy flow in structures, as well as for the study of fluid-structure interaction. These approaches, however, deal with expressions for the structural intensity which are primarily monochromatic and time-averaged. Although this approach leads to an understanding of the "net" energy flow in the time-averaged sense, this perspective does not permit insight into the actual time-dependent phenomena of instantaneous intensity, which portrays how energy actually flows as a function of time. This point is very noteworthy, since entirely differing conclusions 
concerning the physics of a given situation or interaction can be arrived at from these differing perspectives (5).

In this paper, we will briefly present the extension of these previous efforts to express the form of the instantaneous structural intensity in a thin, cylindrical shell. These expressions are then utilized with actual measured data taken from a point-driven, fluid-loaded cylindrical shell, and the instantaneous structural intensity within the shell is displayed. Additionally, the timedependent energy transfer resulting from the fluid-structure interaction is presented and briefly discussed.

\section{THE POINTING VECTOR $(\vec{P}(t)$ : 2-D SHELL THEORY)}

To develop the field intensity vector for thin shells and plates, we follow the method as described in References (1) and (4). In brief, a Taylor series representing the displacements is inserted into the three- dimensional form of the structural intensity, and integrated over the thickness of the shell. The resulting expressions, which we will label intensity resultants and are representative of power flow per unit length, are seen to be immediately expressible in terms of familiar shell notation (i.e. stress and moment resultants), yielding the following general form of the instantaneous structural intensity,

$$
\begin{aligned}
& P_{z}=-\left[\dot{w} Q_{z}+\dot{w}^{(1)} R_{z}+\dot{v} N_{z \phi}+\dot{v}^{(1)} M_{z \phi}+\dot{u} N_{z}+\dot{u}^{(1)} M_{z}+[\ldots]\right] \\
& P_{\phi}=-\left[\dot{w} Q_{\phi}+\dot{w}^{(1)} R_{\phi}+\dot{v} N_{\phi}+\dot{v}^{(1)} M_{\phi}+\dot{u} N_{\phi z}+\dot{u}^{(1)} M_{\phi z}+[\ldots]\right]
\end{aligned}
$$

The velocities (represented as $\dot{w}, \dot{u}$, and $\dot{v}$, and their derivatives with respect to the radial component, i.e. $\dot{w}^{(1)}$, etc.) and resultants are functions of the arguments $(a, \phi, z, t)$. The terms in Eqs. (1) represented by [...] are those integrated quantities which do not result in standard or known representations. It must be emphasized that this in no way implies their insignificance, and also that these terms can be explicitly evaluated (1),(6).

\section{DETERMINATION OF DISPLACEMENT COMPONENTS}

To utilize the previous expressions for the instantaneous structural intensity, it is necessary to know the displacements on the mid-plane (at $r=a$ ), as well as the surface loads or stresses on the upper and lower faces of the shell (at $r=\left(a \pm \frac{h}{2}\right)$ ). It was found that given a knowledge of only the normal displacement and the surface pressure (typically available through the use of nearfield acoustical holography), the tangential displacement components as well as the interior, normal stress could be determined from a solution of many of the standard shell equations. This can be accomplished in a straightforward manner as described in Reference (4). By rearranging the components of the three coupled equations for the vibration of a cylindrical shell, the new system of equations can then be inverted to solve for the unknown tangential displacement components, $u$ and $v$, as well as the unknown interior normal stress.

\section{EXPERIMENTAL APPLICATION}

The surface pressure and normal velocity were measured on a point-driven, fluid-loaded cylindrical shell using nearfield acoustical holography. The experimental data were of course bandlimited, existing over a practical range from $805 \mathrm{~Hz}$ to $10 \mathrm{KHz}$ with a frequency bin width $(\triangle f)$ of $12.2 \mathrm{~Hz}$. This information was then utilized to determine the tangential displacements and interior normal stress, as described above, and subsequently used to determine the components of Eq. (1). Additionally, the frequency spectrum was zeropadded to $30 \mathrm{KHz}$, flipped about this center frequency and the complex conjugate taken to make the spectrum Hermitian. This yielded an effective sampling frequency of $60 \mathrm{KHz}$, or rather a time sample of $1.6 \times 10^{-5}$ seconds. 


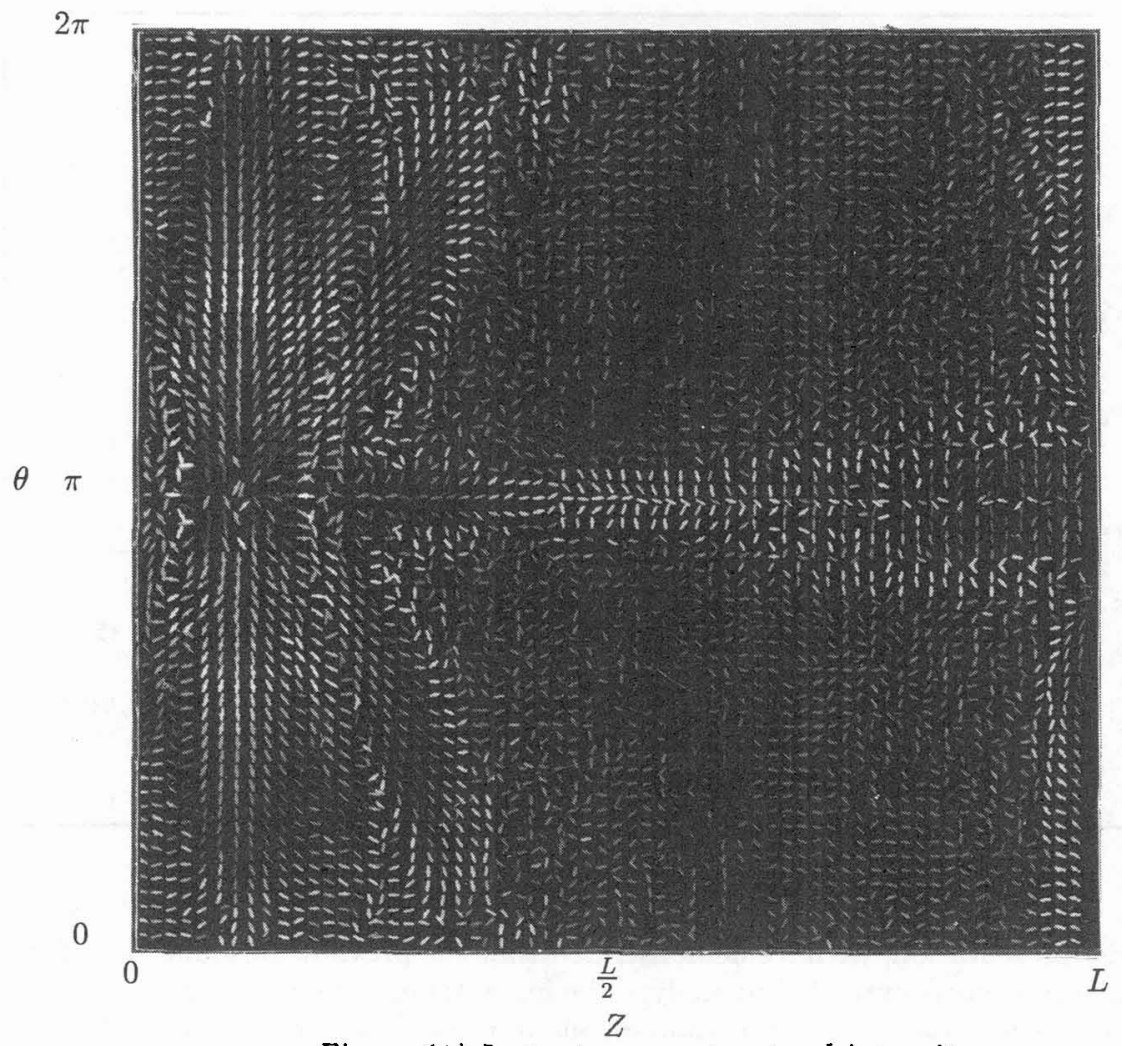

Figure (1) Instantaneous structural intensity.

In Figure (1), the instantaneous structural intensity, due to an impulse delivered by the point force, is displayed in a time snapshot (at $t=11.2 \times 10^{-5} \mathrm{sec}$.). The fast shear wave is first observed to travel straight down the $z$-axis from the source, which is obviously located in the center of the red area. The first slow helical waves are also identified as the two narrow lobes which appear to be forming symmetrically about $\theta=\pi$, making an angle of around $\pm 60^{\circ}$ with the $z$-axis. The major concentration of instantaneous energy flow, however, appears to propagate relatively slowly, expanding outward and identified as being contained within the red region of arrows.

Of additional interest is the energy exchange between the structure and the fluid (7). Performing time and space integrals of the normal component of instantaneous intensity, we can observe the net behavior of this exchange. For example, if we perform the following integration, i.e.

$$
E=\int_{0}^{r} \int_{0}^{L} \int_{0}^{2 \pi} p\left(a+\frac{h}{2}, z, \theta, t\right) \cdot \dot{w}\left(a+\frac{h}{2}, z, \theta, t\right)\left[a+\frac{h}{2}\right] d \theta d z d t
$$

we will obtain a representation of the net energy, $\mathrm{E}$, that is delivered to the fluid over the surface of the cylinder, as a function of the sliding time variable, $\tau$. As can be observed from Figure (2), immediately after the driver delivers the impulse, a large amount of energy is transferred to the fluid. As time progresses, however, energy is seen to be returned to the structure by the fluid. As the system tends to equilibrium, the net quantity of this energy transfer tends to a constant value of $21.5 \%$ of the maximum delivered. In other words, only $21.5 \%$ of the total energy delivered to the fluid by the structure is radiated to the farfield. The other $78.5 \%$ is delivered back into the structure by the fluid, being dissapated by other mechanisms within the cylindrical shell. 


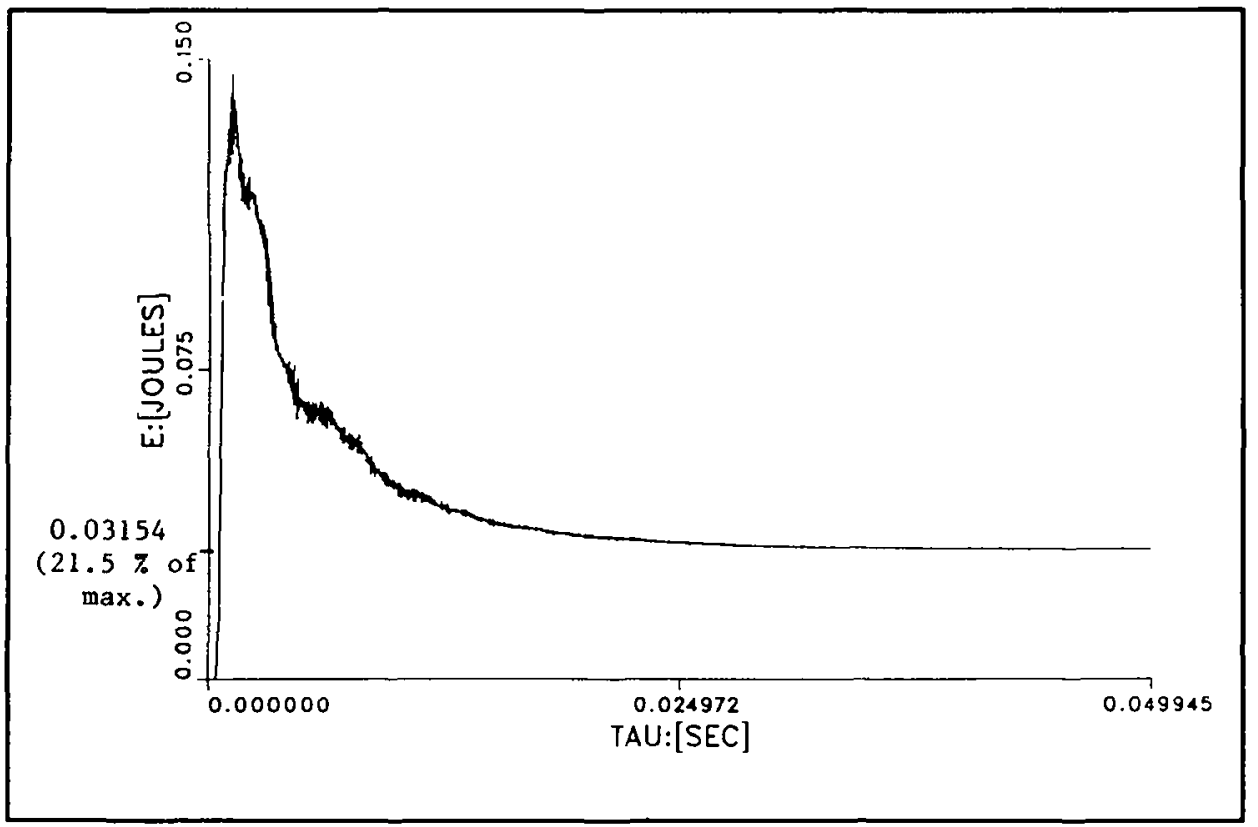

\section{Figure (2) Fluid/Structure energy exchange.}

\section{CONCLUSIONS}

In this brief presentation, we have demonstrated that the previous formulations of structural intensity can be quite easily extended to analyze the instantaneous behavior of energy flow within a structure, as well as to analyze the instantaneous fluid/structure interaction. This approach is very interesting in that the contributions of the various mechanisms of time-dependent energy transport within the structure (i.e. differing wave types, stress and moment resultants, etc.) can be both visually observed, as well as analytically separated for analysis.

The authors would like to acknowledge the efforts of Dr. Brian Houston and Mr. Roger Volk of the Target Facility Section at the Naval Research Laboratory in Washington, D.C., U.S.A., for the outstanding experimental data.

\section{REFERENCES}

1) A.J. Romano, P.B. Abraham, and E.G. Williams, "A Poynting vector formulation for thin shells and plates, and its application to structural intensity analysis and source localization, Part I: Theory", J. Acoust. Soc. Am. 87 (3), 1166-1175 March (1990).

2) E.G. Williams, "Structural intensity in thin cylindrical shells", J. Acoust. Soc. Am. 89 (4), Pt. 1, 1615-1622 April (1991).

3) Proceedings of the 3rd International Congress on Intensity Techniques, Senlis, France, August (1990).

4) A.J. Romano, E.G. Williams, "On the theoretical and experimental applications of a Poynting vector formulation for thin shells and plates", Proceedings of the 3rd International Congress on Intensity Techniques, Senlis, France, August (1990).

5) J.A. Mann,III, J. Tichy, A.J. Romano, "Instantaneous and time-averaged energy transfer in acoustic fields", J. Acoust. Soc. Am. 82 (1), 17-30 July (1987).

6) E. H. Kennard, "The New Approach to Shell Theory: Circular Cylinders," J. Applied Mech., March, 33-40 (1953).

7) J.A. Mann,III, E.G. Williams, K.B. Washburn, and K. Grosh, "Time-domain analysis of the energy exchange betwcen structural vibrations and acoustic radiation using near-field acoustical holography measurements", J. Acoust. Soc. Am. 90 (3), 1656-1664 September (1991). 